\title{
How Do Operational and Design Parameters Effect Biomass Productivity in a Flat-Panel Photo-Bioreactor? A Computational Analysis
}

\author{
Varun Loomba ${ }^{1,2,+}$, Eric von Lieres $1, *$ (D) and Gregor Huber $2, *$ (D) \\ 1 Forschungszentrum Jülich GmbH, Institute of Bio- and Geosciences, IBG-1: Biotechnology, \\ Wilhelm-Johnen-Straße, 52428 Jülich, Germany; vv.loomba@gmail.com \\ 2 Forschungszentrum Jülich GmbH, Institute of Bio- and Geosciences, IBG-2: Plant Sciences, \\ Wilhelm-Johnen-Straße, 52428 Jülich, Germany \\ * Correspondence: e.von.lieres@fz-juelich.de (E.v.L.); g.huber@fz-juelich.de (G.H.) \\ + Current address: Department of Materials Science and Engineering, Norwegian University of Science and \\ Technology, 7491 Trondheim, Norway.
}

check for updates

Citation: Loomba, V.; von Lieres, E.; Huber, G. How Do Operational and Design Parameters Effect Biomass Productivity in a Flat-Panel Photo-Bioreactor? A Computational Analysis. Processes 2021, 9, 1387. https://doi.org/10.3390/pr9081387

Academic Editors: Kristian

Etienne Einarsrud,

Francesca Raganati and Jan Erik Olsen

Received: 30 June 2021

Accepted: 8 August 2021

Published: 10 August 2021

Publisher's Note: MDPI stays neutral with regard to jurisdictional claims in published maps and institutional affiliations.

Copyright: (c) 2021 by the authors. Licensee MDPI, Basel, Switzerland. This article is an open access article distributed under the terms and conditions of the Creative Commons Attribution (CC BY) license (https:/ / creativecommons.org/licenses/by/ $4.0 /)$.

\begin{abstract}
Optimal production of microalgae in photo-bioreactors (PBRs) largely depends on the amount of light intensity received by individual algal cells, which is affected by several operational and design factors. A key question is: which process parameters have the highest potential for the optimization of biomass productivity? This can be analyzed by simulating the complex interplay of PBR design, hydrodynamics, dynamic light exposure, and growth of algal cells. A workflow was established comprising the simulation of hydrodynamics in a flat-panel PBR using computational fluid dynamics, calculation of light irradiation inside the PBR, tracing the light exposure of individual cells over time, and calculation the algal growth and biomass productivity based on this light exposure. Different PBR designs leading to different flow profiles were compared, and operational parameters such as air inlet flowrate, microalgal concentration, and incident light intensity were varied to investigate their effect on PBR productivity. The design of internal structures and lighting had a significant effect on biomass productivity, whereas air inlet flowrate had a minimal effect. Microalgal concentration and incident light intensity controlled the amount of light intensity inside the PBR, thereby significantly affecting the overall productivity. For detailed quantitative insight into these dependencies, better parameterization of algal growth models is required.
\end{abstract}

Keywords: microalgae; computational fluid dynamics; particle tracing; growth modeling; biomass productivity

\section{Introduction}

Sustainably produced biomass represents an important contribution for overcoming the dependence of the economy on fossil resources and reducing the $\mathrm{CO}_{2}$ footprint [1-3]. For different applications, such as fuels, chemicals, and food, different strategies to generate alternative biomass have been pursued, e.g., growing annual or perennial crops for biomassbased energy and products $[4,5]$, development of circular flows in agricultural production systems by utilization of agricultural biomass residues [6,7], and algae cultivation for high-value products [8,9]. Cultivation of microalgae is particularly interesting because it not only generates biomass for a large number of products in various industries, but is associated with additional benefits, such as $\mathrm{CO}_{2}$ capture and possible nutrient uptake from wastewater [10-12]. In addition, microalgae do not need arable land, so they do not directly compete with food crops for land usage. However, to develop their full potential and increase the economic feasibility of algae cultivation, further process optimization is needed [13]. Efficiency of algal cultivation is determined by a complex interplay of photobioreactor (PBR) design and operation conditions. Among these parameters, the light 
available to individual microalgal cells is the most crucial parameter in determining their photosynthetic efficiency. Loomba et al. $(2018)[14,15]$ discussed in detail the calculation of dynamic light exposure of individual algal cells in a flat-panel PBR and how it is affected by the operational parameters of the PBR. This light exposure can further be used to mathematically calculate the growth of individual cells and hence the productivity of the PBR [16], which is thus affected by operational parameters and the design of the PBR [17]. Operational parameters such as microalgal concentration determine the amount of light intensity inside the PBR, whereas air flowrate controls the mixing of cells and their light exposure, affecting the overall productivity of the PBR. The design of the internal structures in the PBR also determines the flow profile of the liquid medium and microalgal cells, thus affecting their light exposure [18]. Internal geometrical factors include the position and size of inlet holes for air sparging, and the thickness, position, and location of internal components, such as baffles and a middle plate (in the case of an airlift PBR). Air inlet flowrates have been optimized for maximizing productivity by analyzing the turbulence and mixing inside the PBR $[18,19]$. Other improvement efforts concerned the internal structures of the PBR, such as baffles [20,21], bends [22,23], static mixers [19,24], and bottom and top clearance and riser widths in airlift PBRs [25-27]. Most of these studies for improving the operational or design parameters involved flow parameters, such as turbulent kinetic energy, mixing, and dead zone volumes. Some studies have computationally calculated the growth rates of individual cells to optimize the PBR performance (see Table 3 in Gao et al. (2018) [28], and [29]). Dynamic light exposure has been shown to have no impact on algal growth if instantaneous growth models are used [30-32]. Systematic studies of different operational parameters using dynamic growth models that include the effect of the light history of individual cells are lacking.

In this study, the effect of several operational and design parameters on the productivity of a laboratory-scale flat panel PBR was computationally analyzed using a dynamic growth model. Our working hypothesis was that the air inlet flowrates do not have a significant effect on the productivity in contrast to parameters such as internal design, incident light intensity, microalgal concentration, and light incident from different surfaces. Computational fluid dynamics (CFD) was used as a tool to determine the flow profiles of liquid and microalgal cells, which were further combined with independently calculated light intensity profiles to obtain their dynamic light exposure. This was further used to calculate growth rates of individual cells and PBR productivity (Figure 1).

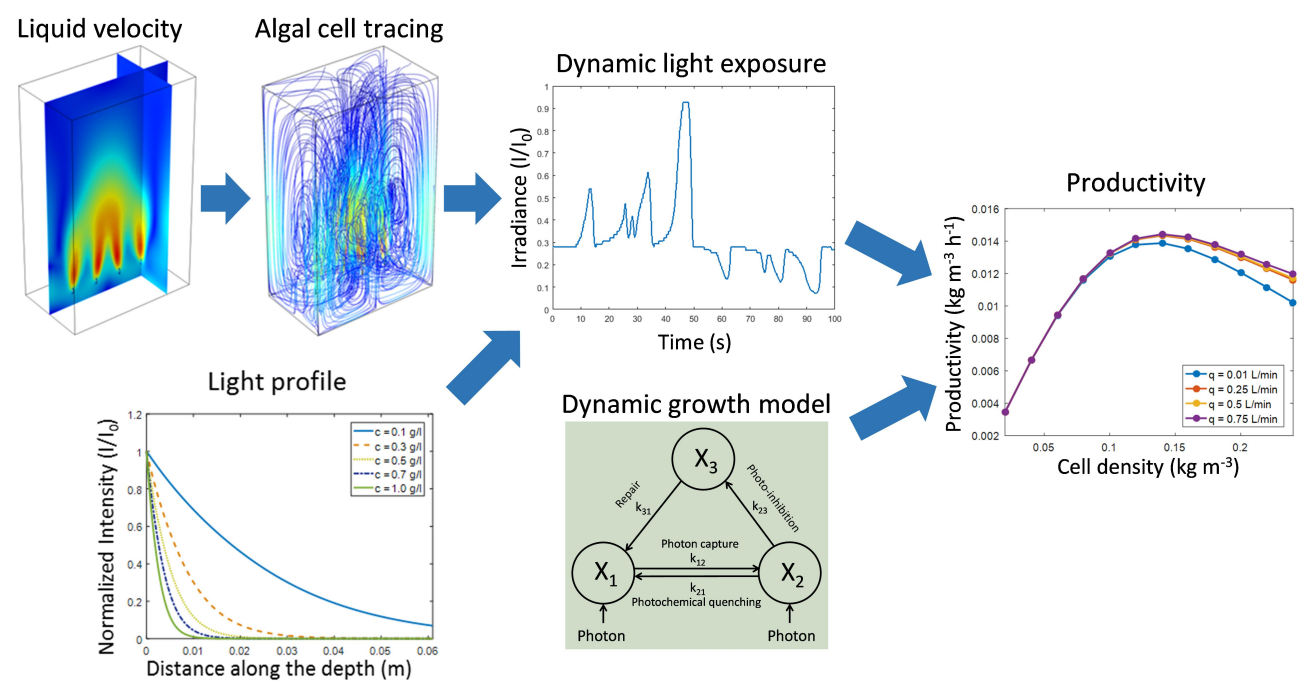

Figure 1. Schematic of workflow in the present study: liquid velocities obtained from CFD simulations of a PBR enabled calculation of flow profiles of many individual algal cells by particle tracing, which together with independently calculated light intensity profiles resulted in dynamic light exposure of individual algal cells. This was combined with growth modeling to obtain insights into the dependence of biomass productivity on operational parameters. 


\section{Materials and Methods}

\subsection{PBR Design}

In this study, a standard flat panel PBR (Figure 2) was used as a reference ("Standard Design"). It is a cuboidal-shaped vessel with dimensions of approx. $10 \times 6 \times 21 \mathrm{~cm}$ (width $\times$ depth $\times$ height) and is typically filled with up to $1 \mathrm{~L}$ of fluid [33].

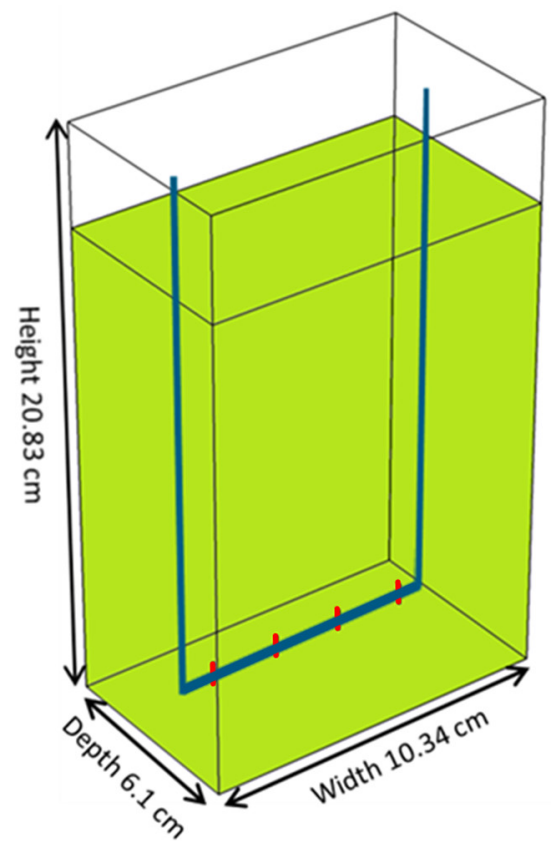

Figure 2. Three-dimensional schematic of the flat panel PBR used as the standard in this study.

To study the effect of design parameters on the PBR productivity, two alternate designs were considered: in "Alternate Design A", the four gas inlet holes were moved from the middle to a quarter of the distance from the wall along the depth of the PBR; in addition to this, in "Alternate Design B" a plate was inserted in the middle to transform it into an airlift PBR (Figure 3). In this case, as is typical in airlift PBRs, the region above the inlet holes is called the "riser" and the region where liquid comes down is called the "downcomer". The selection of the two alternate designs was inspired by previous computational studies on hydrodynamics and growth of algae in PBRs with different internal designs $[32,34]$. The purpose of the alternate designs was to change the flow profiles of the water and microalgal cells, such that the main movement is in a single loop along the depth, compared to the Standard Design in which the liquid and cells move in two loops above the inlet [14,15]. At high microalgal concentrations, the light/dark border is close to the wall of light incidence. Hence, cells are expected to visit the light zone more frequently if they are moving in one loop in the alternate designs, compared to the Standard Design, in which some cells moving in loops in the back half of the PBR may not receive a large amount of light, leading to a low productivity of the PBR. 
(a) Standard Design

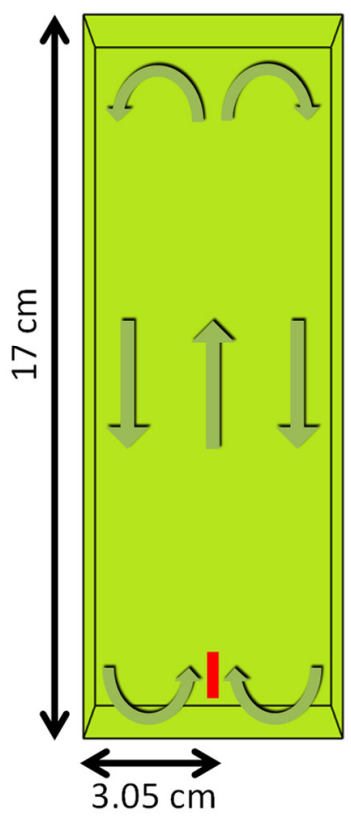

(b) Alternate Design A

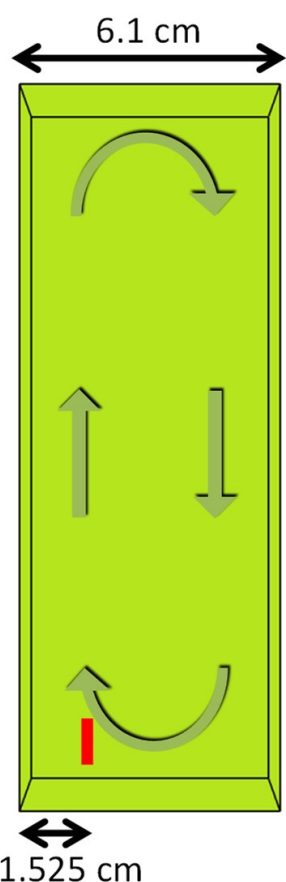

(c) Alternate Design B

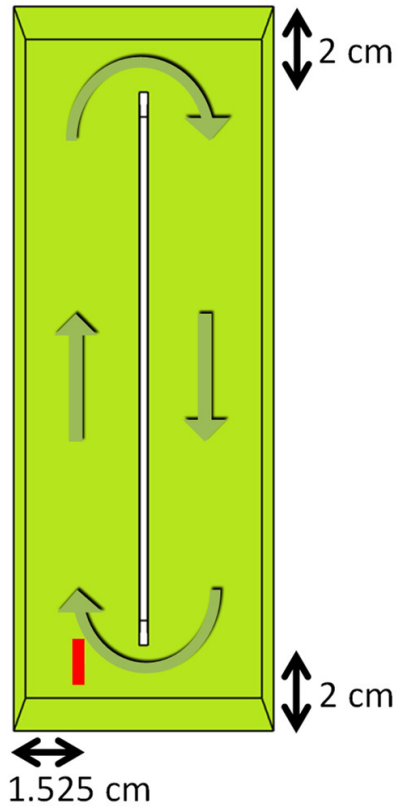

Figure 3. Schematic side view of the three photo-bioreactor designs investigated in this study: (a) Standard Design with gas inlet tube in the middle; (b) Alternate Design A with inlet moved to front; (c) Alternate Design B with additional separating plate. Green arrows indicate directions of main fluid movement, red bars show the positions of gas inlet tubes. The width of all three reactors is $10 \mathrm{~cm}$.

\subsection{Simulations}

Fluid dynamic simulations were performed to calculate the flow profiles of air and water inside the PBR. Water velocities were further used to track the path of 10,000 randomly distributed microalgal cells over a time of $100 \mathrm{~s}$. All these simulations were performed using the CFD module of COMSOL Multiphysics ${ }^{\circledR}$ v. 5.2a (COMSOL AB, Stockholm, Sweden). The inlet pipe shown in Figure 2 was excluded to speed up the simulations. Independently of the simulations, the light intensity profiles inside the different designs were calculated by numerically solving the radiative transfer equation (RTE) for uniform external incidence. These light intensity profiles were combined with individual cell paths to obtain their dynamic light exposure. The complete process is explained in detail in Loomba et al. (2018) $[14,15]$. Light exposure of individual cells was used to calculate the productivity of the PBR. In addition to design parameters such as position of inlet holes (Figure 3) and surface of light incidence, several operational parameters, such as air inlet flowrate, microalgal concentration, and incident light intensity, were varied in the simulations and their effect on the overall PBR productivity was analyzed.

The four different flowrates used in this study were $0.01,0.25,0.5$, and $0.75 \mathrm{~L} / \mathrm{min}$. These flowrates were chosen to compare the effect of low and high flowrates, i.e., flowrates were varied in orders of magnitude and within the range of high flowrates. The values $0.25-0.75 \mathrm{~L} / \mathrm{min}$ are in the same order of magnitude as those used in other numerical and experimental studies of rectangular PBRs [32-35], whereas the value $0.01 \mathrm{~L} / \mathrm{min}$ was chosen to investigate the variation in productivity of the PBR for an extremely low flowrate. Because microalgal concentration inside the PBR affects the light profile, calculations were also performed at several microalgal concentrations, mainly in the range from 0.05 to $0.5 \mathrm{~kg} / \mathrm{m}^{3}$; see Results and Discussion. High concentrations lead to high light absorption, thus decreasing the light intensity available to cells far away from the incident light. Hence, incident light intensities were also varied from 500 to $2500 \mu \mathrm{E} / \mathrm{m}^{2} \mathrm{~s}$ to study their effect on the overall PBR performance. 


\subsection{Growth Rate and Productivity Modeling}

Several mathematical models have been proposed in the literature to calculate microalgal growth based on the light intensity received by individual cells [16,36]. These models include the effect of processes such as photosynthesis, respiration, and photo-inhibition. In the current study, two of these models were selected and implemented, with and without including the effect of the light history of the cells. The first model was proposed by Aiba (1982) [37] and parameterized by Pruvost et al. (2008) [30] for the microalgal species Chlamydomonas reinhardtii. It is an instantaneous or "steady state" model that does not account for the light history of the cells. Photosynthesis, respiration, and photo-inhibition are included in this model by:

$$
\mu=\frac{\mu_{m} I}{K_{I}+I+\frac{I^{2}}{K_{I I}}}-\mu_{s}
$$

where $\mu$ is the specific growth rate, $I$ is the instantaneous light intensity received by an individual cell, $\mu_{s}$ is the respiration rate, and $\mu_{m}, K_{I}$, and $K_{I I}$ are constants. The two terms on the right-hand side of Equation (1) describe the photosynthetic rate and the respiration rate, respectively. The respiration rate is assumed to be independent of the light intensity received by individual cells. A Michaelis-Menten type of description is used for the photosynthetic rate, with an additional term $\left(I^{2} / K_{I I}\right)$ included in the denominator accounting for photo-inhibition.

The other model implemented in this study was proposed by Eilers and Peeters (1988) [38], and includes the effect of the light history of individual cells. This model defines all photosynthetic units (PSUs) in the cells to be in one of three states: ground state $\left(X_{1}\right)$, excited state $\left(X_{2}\right)$, or damaged state $\left(X_{3}\right)$. PSUs change these states depending on the amount of light intensity received. Figure 4 explains the dynamics between these three states in a schematic diagram. The fractions of PSUs present in each of these states are given by $x_{1}, x_{2}$, and $x_{3}$. PSUs shift from the ground state $\mathrm{X}_{1}$ to the excited state $\mathrm{X}_{2}$ on receiving light and can further reach the damaged state $X_{3}$ by absorbing more light. PSUs in state $X_{2}$ can also fall back to $X_{1}$ by utilizing light for photosynthesis via the photochemical quenching process. PSUs in the state $X_{3}$ can release excess light energy as heat, thereby returning to $X_{1}$. All chemical reactions taking place in the photosynthetic process are lumped together in the photochemical quenching process. The maximum photosynthetic rate occurs when all the cells are in state $X_{2}$. Thus, fraction $x_{2}$ is a measure of the ratio of the photosynthetic rate to the maximum photosynthetic rate possible [39].

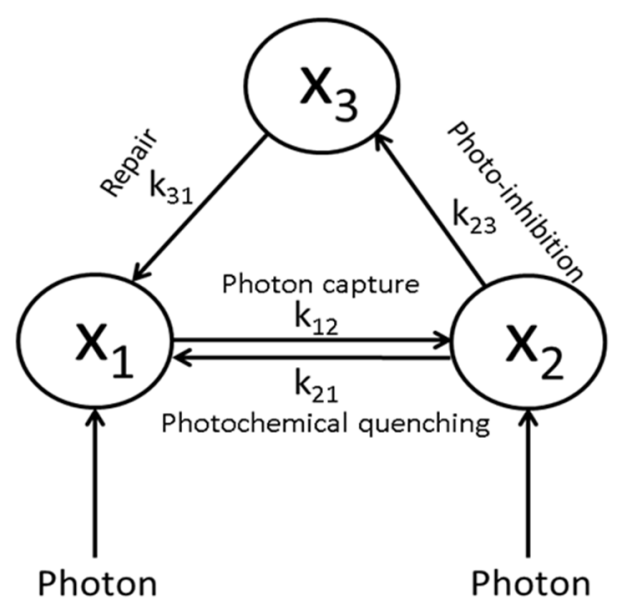

Figure 4. Schematic diagram showing the three states of the dynamic growth model for microalgal cells according to Eilers and Peeters (1988) [38]. 
The following equations describe the effect of light on the dynamics of the PSUs.

$$
\begin{gathered}
\frac{d x_{1}}{d t}=-k_{12} I x_{1}+k_{21} x_{2}+k_{31} x_{3} \\
\frac{d x_{2}}{d t}=k_{12} I x_{1}-k_{21} x_{2}-k_{23} I x_{2} \\
\frac{d x_{3}}{d t}=k_{23} I x_{2}-k_{31} x_{3}
\end{gathered}
$$

where $k_{12}, k_{21}, k_{23}$, and $k_{31}$ are constants. Because the total number of PSUs is constant, the sum of all fractions in states $X_{1}, X_{2}$, and $X_{3}$ must be 1 . This is used as a constraint to solve the above equations.

$$
x_{1}+x_{2}+x_{3}=1
$$

In order to convert the photosynthetic rates into growth rates, fraction $x_{2}$ is multiplied by a conversion factor:

$$
\mu=k_{\text {conv }} x_{2}-M e,
$$

where $\mu$ is the specific growth rate, $k_{\text {conv }}$ is the conversion factor, and $M e$ is the maintenance (or respiration) term for the microalgal cell.

This model has been parameterized by Wu and Merchuk (2001) [40], Zarmi et al. (2013) [41], and Gao et al. (2017) [31] (Table 1). Wu and Merchuk (2001) [40] used experimental data of the marine algae Porphyridium sp. to calculate the values of the constants; Gao et al. (2017) [31] obtained the parameters from fitting experimental data for the growth of Chlorella vulgaris; and Zarmi et al. (2013) [41] obtained the parameter values from a comparison with existing PI curves without specifying the microalgal species.

Table 1. Coefficients for the three-state growth model estimated by Wu and Merchuk (2001) [40], Zarmi et al. (2013) [41], and Gao et al. (2017) [31].

\begin{tabular}{clll}
\hline Coefficient & Wu and Merchuk (2001) & \multicolumn{1}{c}{ Zarmi et al. (2013) } & \multicolumn{1}{c}{ Gao et al. (2017) } \\
\hline$k_{12}$ & $1.935 \times 10^{-3} \mathrm{~m}^{2} / \mu \mathrm{E}$ & $0.542 \mathrm{~m}^{2} / \mu \mathrm{E}$ & $7.253 \times 10^{-4} \mathrm{~m}^{2} / \mu \mathrm{E}$ \\
$k_{21}$ & $0.146 \mathrm{~s}^{-1}$ & $70 \mathrm{~s}^{-1}$ & $9.485 \times 10^{-3} \mathrm{~s}^{-1}$ \\
$k_{23}$ & $5.785 \times 10^{-7} \mathrm{~m}^{2} / \mu \mathrm{E}$ & $2.72 \times 10^{-5} \mathrm{~m}^{2} / \mu \mathrm{E}$ & $1.703 \times 10^{-8} \mathrm{~m}^{2} / \mu \mathrm{E}$ \\
$k_{31}$ & $4.796 \times 10^{-4} \mathrm{~s}^{-1}$ & $0.1 \mathrm{~s}^{-1}$ & $9.968 \times 10^{-6} \mathrm{~s}^{-1}$ \\
\hline
\end{tabular}

There is a very high degree of uncertainty in the parameter values of Wu and Merchuk (2001) [40], as shown by the 95\% confidence intervals for all coefficients: some parameters varied within $300-400 \%$ of the values in Table 1, whereas others had a variation of two to three orders of magnitude. The certainty of the parameter values obtained by Zarmi et al. (2013) [41] and Gao et al. (2017) [31] has not been reported.

Because of the vast differences and the high degree of uncertainty in the existing parameterizations, in this study the parameter values were varied within a certain range. To ensure compatibility with the steady state model, which contains three parameters (Equation (1)), we chose different values of two parameters, $k_{21}$ and $k_{23}$, from the five parameters of the dynamic model (Equations (2)-(6)), and calculated the remaining three parameters of the dynamic model by comparison with the steady state model. All the chosen values of $k_{21}$ and $k_{23}$ were within the $95 \%$ confidence intervals specified by Wu and Merchuk (2001) [40]. The value of the respiration term proposed by Pruvost et al. (2008) [30] was considered because it is independent of light intensity.

The growth rates determine the speed at which microalgal cells grow but do not articulate the absolute biomass accumulation. Lower microalgal concentration is preferred for high growth rates because high light intensities are available inside the PBR, but leads to lower absolute biomass accumulation. To attain the optimal microalgal concentration leading to maximal biomass accumulation, PBR productivity $P$, i.e., change in biomass per 
unit volume per unit time, was calculated from the specific growth rates by the following relation [42]:

$$
P=\mu C_{a v g},
$$

where $C_{\text {avg }}$ is the average microalgal concentration during the time step. The total simulated time was $100 \mathrm{~s}$, during which time there was no significant change in concentration. Therefore, concentration was assumed to be constant during the simulations.

\section{Results and Discussion}

\subsection{Fluid Characteristics}

There is a clear difference between the flow characteristics of the Standard Design and those of the two Alternate Designs for an air inlet flowrate of $0.5 \mathrm{~L} / \mathrm{min}$ (Figure 5). Overall, the fluid carrying microalgal cells moved in two loops along the depth of the PBR in the Standard Design, and in a single big loop in both of the Alternate Designs. The presence of the central separating plate in Alternate Design B marks the clear division between a highly turbulent riser region and a laminar downcomer region, where almost no bubbles were present. The highest water velocity, bubble-induced turbulence, and air volume fraction were noted in the regions above the inlet holes, which were the central region in the Standard Design and the region near the front wall in both of the Alternate Designs. Because turbulence was highest in these regions, mixing was also intense. The profiles of velocity and turbulent kinetic energy were similar to the results from previous studies of rectangular PBRs with larger volumes [21,24,34]. Here and in the following, we call the surface near the inlets in the Alternate Designs the "front wall", whereas the surface distant from the inlets is termed the "back wall".

\subsection{Light/Dark Patterns}

The light exposure of individual cells was investigated by combining the simulated particle traces and the calculated light intensity profiles. This was used to analyze the duration continuously spent by cells in the light and dark zones, respectively. Cells staying in the dark zone continuously for a long time are undesirable because they may consume stored nutrients, leading to a possible loss of biomass. Here, the dark zone was defined as the region where the light intensity was lower than the compensation point, i.e., a light intensity at which the specific growth rate is zero. The position of the light/dark (L/D) border was calculated from Equation (1). The light zone extended only to a few millimeters or centimeters for moderate and high microalgal concentrations $\left(>0.5 \mathrm{~kg} / \mathrm{m}^{3}\right)$, and a moderately high light intensity $\left(1000 \mu \mathrm{E} / \mathrm{m}^{2} \mathrm{~s}\right)$ incident on one surface of the PBR. Under these conditions, cells moving in a loop at the back of the PBR do not receive light, whereas the single loop in both Alternate Designs leads to more frequent visits to the light zone, which is expected to have a beneficial effect on productivity. 
(A1)

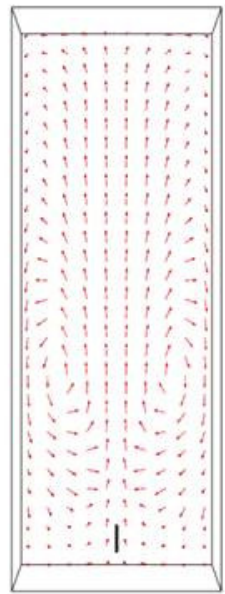

(B1)

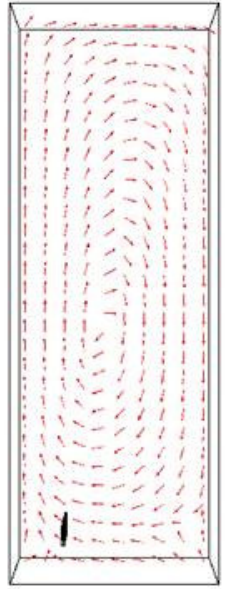

(C1)

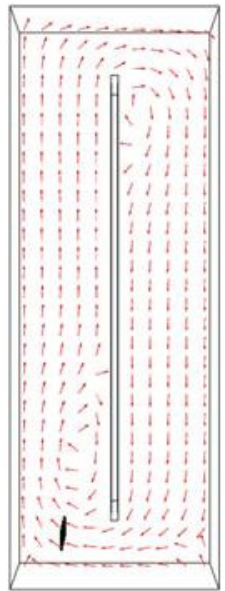

(A2)

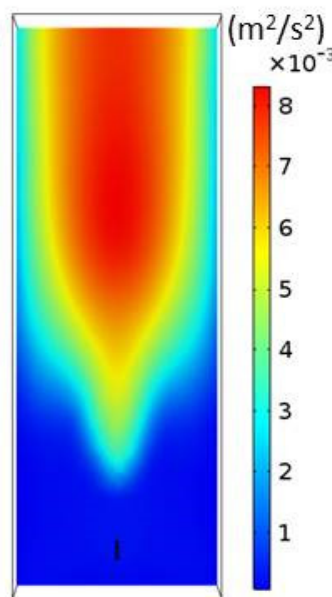

(B2)

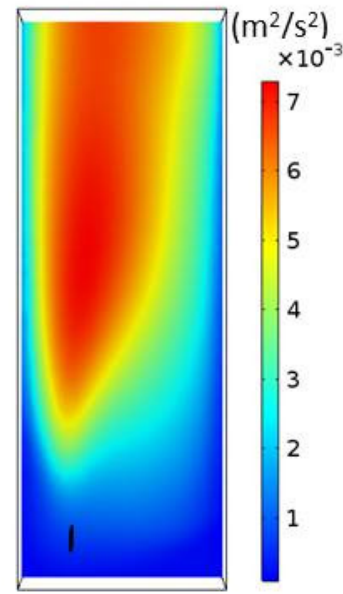

(C2)

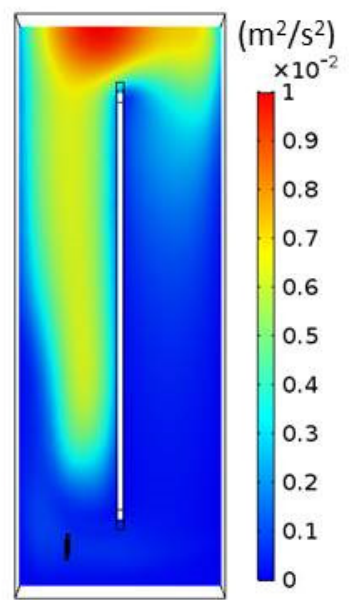

(A3)

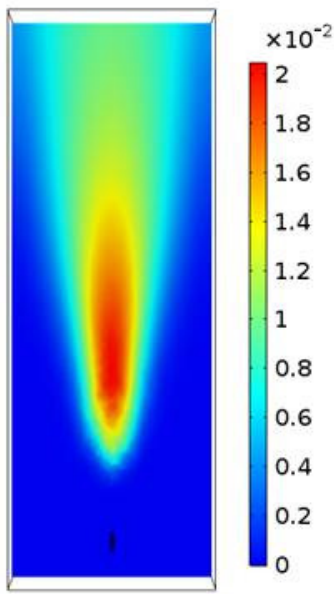

(B3)

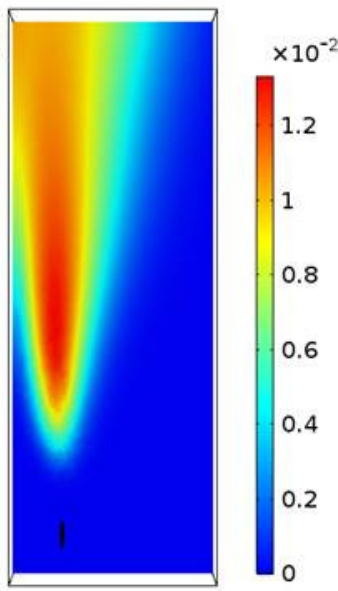

(C3)

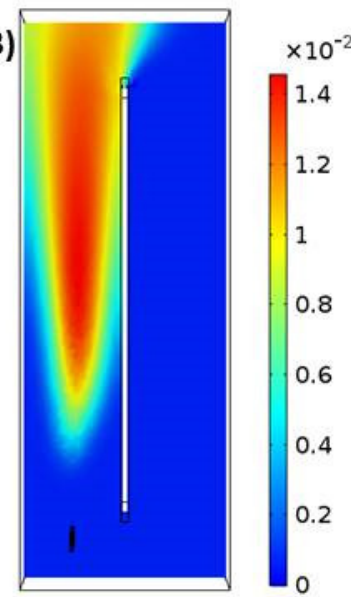

Figure 5. Hydrodynamic simulations of the three PBR designs, using an air inlet flowrate of $0.5 \mathrm{~L} / \mathrm{min}$ for all cases. Comparison of results along depth and height from the (A) Standard Design, (B) Alternate Design A, and (C) Alternate Design B. Properties shown are (1) normalized water velocity vectors, (2) turbulent kinetic energy, and (3) air volume fraction.

The distributions of the durations continuously spent in the dark zone by 10,000 cells are shown in Figure 6 as histograms for the different designs. A total light intensity of $1000 \mu \mathrm{E} / \mathrm{m}^{2} \mathrm{~s}$ was incident from either one or both sides of the PBR. The total simulated time was $100 \mathrm{~s}$, and a constant microalgal concentration of $0.5 \mathrm{~kg} / \mathrm{m}^{3}$ was assumed. Each entry in the histogram corresponds to one visit of a microalgal cell to the dark zone; thus, single cells can have multiple entries in the histogram. We chose this analysis of L/D cycles 
in the time domain, previously used by [24,43], rather than a frequency analysis, because its results can be directly related to dynamic growth modeling.
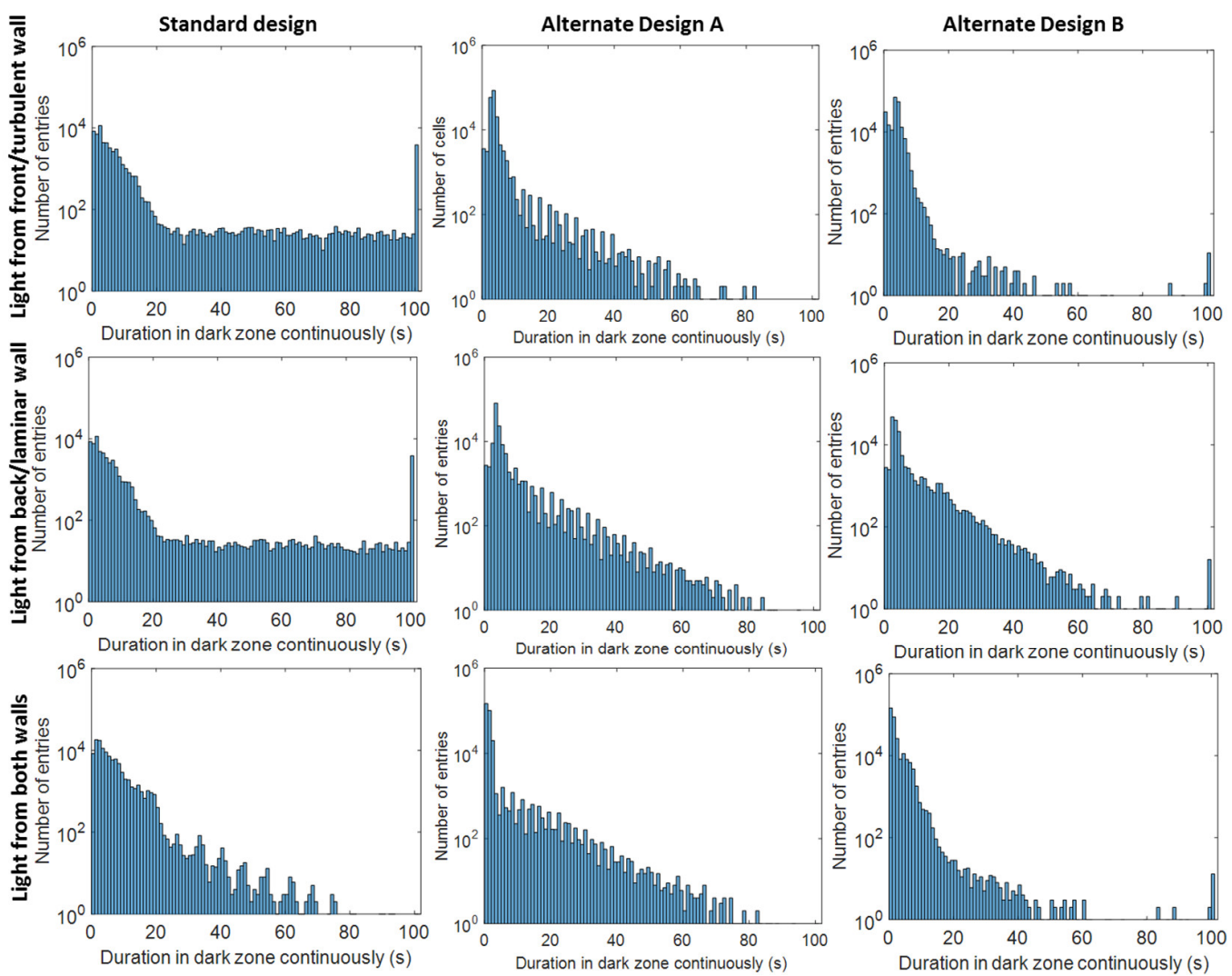

Figure 6. Time continuously spent in the dark zone by microalgal cells for three PBR designs and light incident from the turbulent side (front wall), laminar side (back wall), and both sides. Parameters used in the simulation were air flowrate of $0.5 \mathrm{~L} / \mathrm{min}$, concentration of $0.5 \mathrm{~kg} / \mathrm{m}^{3}$, and total incident intensity of $1000 \mu \mathrm{E} / \mathrm{m}^{2} \mathrm{~s}$.

In the Standard Design with its symmetric flow profile along the depth, the overall $\mathrm{L} / \mathrm{D}$ patterns (Figure 6) confirmed that changing the light incidence from the front to the back wall had no effect. This was different in the case of the Alternate Designs, where the flow profiles are not symmetric. Here, the L/D border was in the turbulent region for the case of light incident from the front wall, approximately at a quarter distance from the incident surface. Compared to the Standard Design, there were more entries in the range of 0 to $5 \mathrm{~s}$ and fewer entries corresponding to higher times $(>30 \mathrm{~s})$, because the cells moved frequently between the light and the dark zones. For the case of light incident from the back wall, there were more entries in the range of high times $(>30 \mathrm{~s})$ in both Alternate Designs A and B. Almost $40 \%$ of the total cells in the Standard Design stayed in the dark zone for all of the simulated time of $100 \mathrm{~s}$. The number of cells remaining in the dark all the time was reduced in the Alternate Designs A and B to an insignificant number, i.e., less than $0.2 \%$ of the total number of cells. Some of these cells were stuck in a small circulation that formed near the central plate at the top of the downcomer region. The difference in the L/D patterns of the individual cells between the designs was quantified by summing the entries of the distribution tail at longer durations between 30 and $99 \mathrm{~s}$ (Table 2). As expected, this sum was almost the same in the Standard Design for light incident from the front and back walls, but dropped considerably in the Alternate Designs, reaching a minimum for Alternate Design B with light incident from the front. 
Table 2. Characteristics of durations continuously spent in dark zones for different designs and light incidence from different sides. Simulations were performed with an air flowrate of $0.5 \mathrm{~L} / \mathrm{min}$, concentration of $0.5 \mathrm{~kg} / \mathrm{m}^{3}$, and total incident intensity of $1000 \mu \mathrm{E} / \mathrm{m}^{2} \mathrm{~s}$.

\begin{tabular}{lccccccccc}
\hline PBR Design & \multicolumn{3}{c}{ Standard Design } & \multicolumn{3}{c}{ Alternate Design A } & \multicolumn{3}{c}{ Alternate Design B } \\
\hline Light Incidence & Front & Back & Both & Front & Back & Both & Front & Back & Both \\
\hline No. of cells spending 100 s in dark & 3843 & 3797 & 1 & 0 & 0 & 0 & 11 & 16 & 13 \\
No. of entries 30 to 99 s & 1823 & 1796 & 541 & 974 & 1278 & 1115 & 79 & 1105 & 130 \\
Maximum time spent in dark zone (s) & - & - & 53 & 65 & 73 & 71 & 25 & 64 & 33 \\
\hline
\end{tabular}

$\mathrm{L} / \mathrm{D}$ patterns were also calculated for light of the same total intensity but incident from both walls of the PBR (i.e., an equal intensity of $500 \mu \mathrm{E} / \mathrm{m}^{2} \mathrm{~s}$ incident from each side simultaneously). This increased the extent of the light zone to $2.7 \mathrm{~cm}(1.35 \mathrm{~cm}$ from each side) compared to approx. $1.6 \mathrm{~cm}$ for light incidence from one side, always at a microalgal concentration of $0.5 \mathrm{~kg} / \mathrm{m}^{3}$. As light entered from both sides, cells moving in the back loop in the Standard Design also received light, leading to almost zero cells staying in the dark zone all the time (Figure 6 and Table 2), and significantly reducing the tail of the distribution (Table 2). In the Alternate Designs, light incident from both sides led to more entries in the range of 0 to $5 \mathrm{~s}$, but did not reduce the distribution tails compared to incidence from the front wall (Table 2). Independent of the light incidence, the number of very short durations spent in the dark increased in the alternate design compared to the Standard Design. This is consistent with findings by Huang et al. (2014) [24], who showed that inserts reducing the loop size led to a narrowing of the distribution of $\mathrm{L} / \mathrm{D}$ cycles compared to the Standard Design.

To obtain a proxy for the maximum time continuously spent by microalgal cells in the dark zone, exponential trend lines (i.e., straight lines in the logarithmic scale) were fitted to the histograms of Figure 6 for durations $>20$ s, and the intercepts of these lines with the time axis (at number of entries $=1$ ) were calculated. This fitting was not possible for the Standard Design and single side incidence because the maximum time continuously spent in the dark zone tail was much higher than $100 \mathrm{~s}$ in these cases. The calculated values for the other cases (Table 2) confirmed that the maximum time spent in the dark by individual cells can be reduced by changing the interior design and thus the flow profile of the PBR. The lower maximum time for Alternate Design B compared to Alternate Design A was likely caused by the better directional flow of microalgal cells due to the presence of a central plate. Similar to the distribution tails, the maximum time spent in the dark zone was affected by light incidence from both sides, particularly in the Standard Design (Table 2). In summary, L/D patterns in the Standard Design were significantly improved by changing the light incidence from one side to both sides, whereas the Alternate Designs did not benefit from this illumination strategy. Independent of light incidence, Alternate Design B showed the most promising L/D patterns.

The quantitative results of Table 2 and Figure 6 clearly are valid for the applied parameter set only. However, the results are illustrative and representative, because the trends and underlying mechanisms also hold for other values of the operational parameters that might lead to different positions of the $\mathrm{L} / \mathrm{D}$ border.

\subsection{Biomass Productivity}

The dynamic light exposure of all 10,000 cells was used to calculate the specific growth rates of individual cells using both steady state and dynamic models (Equations (1)-(6)). Higher light intensities experienced by individual cells obviously lead to higher specific growth rates, but very high incident light intensities are fatal for microalgal cells near the incident surface. At low microalgal concentrations, light penetrates deeper into the PBR leading to high specific growth rates, but absolute biomass accumulation is low. Therefore, biomass productivity, i.e., rate of change of mass per unit time per unit volume of the solution, was calculated according to Equation (7) and used as a measure of the PBR 
performance. When the light history is not accounted for, maximum productivity occurs at a microalgal concentration at which the L/D border is exactly at the back wall, such that the entire PBR is in the light zone and no light exits, regardless of the air inlet flowrate or interior design, and productivity is only determined by the light path length [44]. For a lower microalgal concentration, light leaves the PBR at the back; thus, not all energy irradiated is utilized by microalgal cells. In contrast, for higher microalgal concentrations, some portion of the PBR is in the dark, leading to lower productivity. The height and position of the productivity maximum depends non-linearly on the incident light intensity (Figure 7). The shape of these curves fits very well to previous experimental results [45,46]. The concentration at which productivity was maximal increased with increasing incident light intensities because the criterion "light zone extending to the back surface of the PBR" occurred at higher microalgal concentrations. However, the gain in maximum productivity decreased with increasing incident light due to increasing photo-inhibition rates near the incident surface. At very low concentrations $\left(<0.05 \mathrm{~kg} / \mathrm{m}^{3}\right)$, there was an excess of light throughout the PBR, so that very high incident light $\left(>2000 \mu \mathrm{E} / \mathrm{m}^{2} \mathrm{~s}\right)$ even led to a small reduction of biomass productivity due to a high rate of photo-inhibition (Figure 7). Thus, very high incident light intensities cannot be expected to contribute to a further increase in productivity.

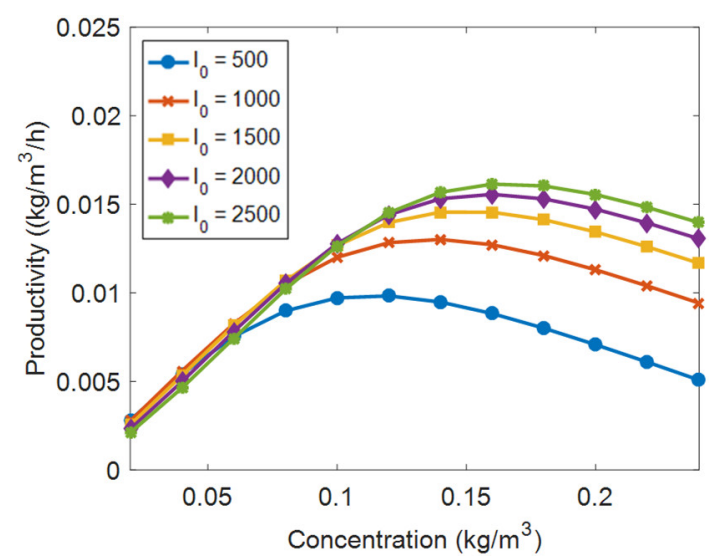

Figure 7. Biomass productivity varying with algal concentration and incident light intensity $\mathrm{I}_{0}$ $\left[\mu \mathrm{E} / \mathrm{m}^{2} \mathrm{~s}\right]$ for air inlet flowrate of $0.5 \mathrm{~L} / \mathrm{min}$, using the steady state growth model and the Standard Design of the PBR.

Biomass productivity may be potentially affected by the air inlet flowrate of the PBR, if a varying degree of mixing changes the dynamic light exposure of the algal cells. As theoretically postulated and seen in other simulation studies [30,32], no such effect can be observed if calculating biomass productivity with the steady state growth model (Figure $8 \mathrm{~b}$ ), because this model does not take into account the light history of individual cells. Using a certain parameterization of the dynamic growth model, the productivity increased with a change from a very low $(0.01 \mathrm{~L} / \mathrm{min})$ to a high $(0.5 \mathrm{~L} / \mathrm{min})$ air inlet flowrate because of higher mixing (Figure 8 a). However, changing the air flowrate by $50 \%$ around the value of $0.5 \mathrm{~L} / \mathrm{min}$ had only a minimal effect on mixing, and hence an insignificant effect on productivity (Figure 8a). This result is similar to the findings of Olivieri et al. (2015) [39], who observed that the photosynthetic rate as a function of concentration does not increase over a certain limit with increasing turbulent diffusivity. 

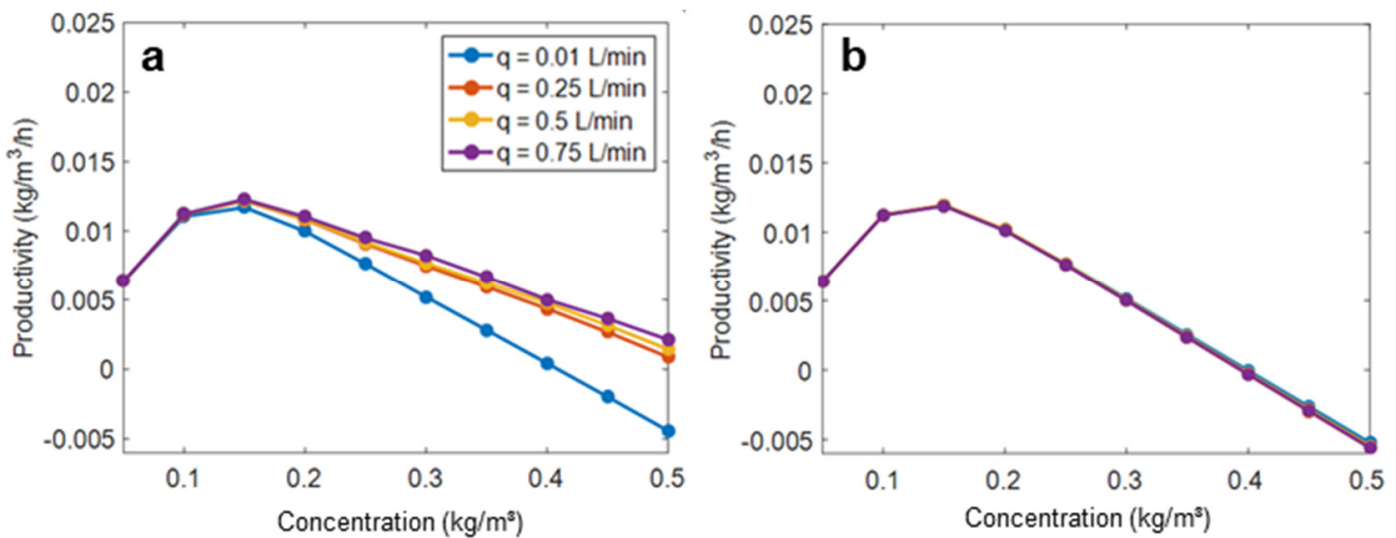

Figure 8. Biomass productivity in the Standard Design PBR at various microalgal concentrations and air flowrates, calculated using (a) the dynamic growth model with parameters $k_{21}=0.1 \mathrm{~s}^{-1}, k_{23}=10^{-4} \mathrm{~m}^{2} / \mu \mathrm{E}$; and (b) the steady state growth model.

Altering the internal design of the PBR changed the dynamic light exposure of the microalgal cells by affecting their flow patterns. Durations continuously spent in the dark zone were greatly reduced in the Alternate Designs compared to the Standard Design (Figure 6). In the steady state growth model, this had a negligible effect on biomass productivity (upper row of Figure 9), because all cells on average absorbed the same total light intensity, and growth was calculated based solely on the instantaneous light intensity. However, taking the light history of the individual cells into account by applying the dynamic growth model, the productivity was much higher for the Alternate Designs than for the Standard Design at all microalgal concentrations (lower row of Figure 9).

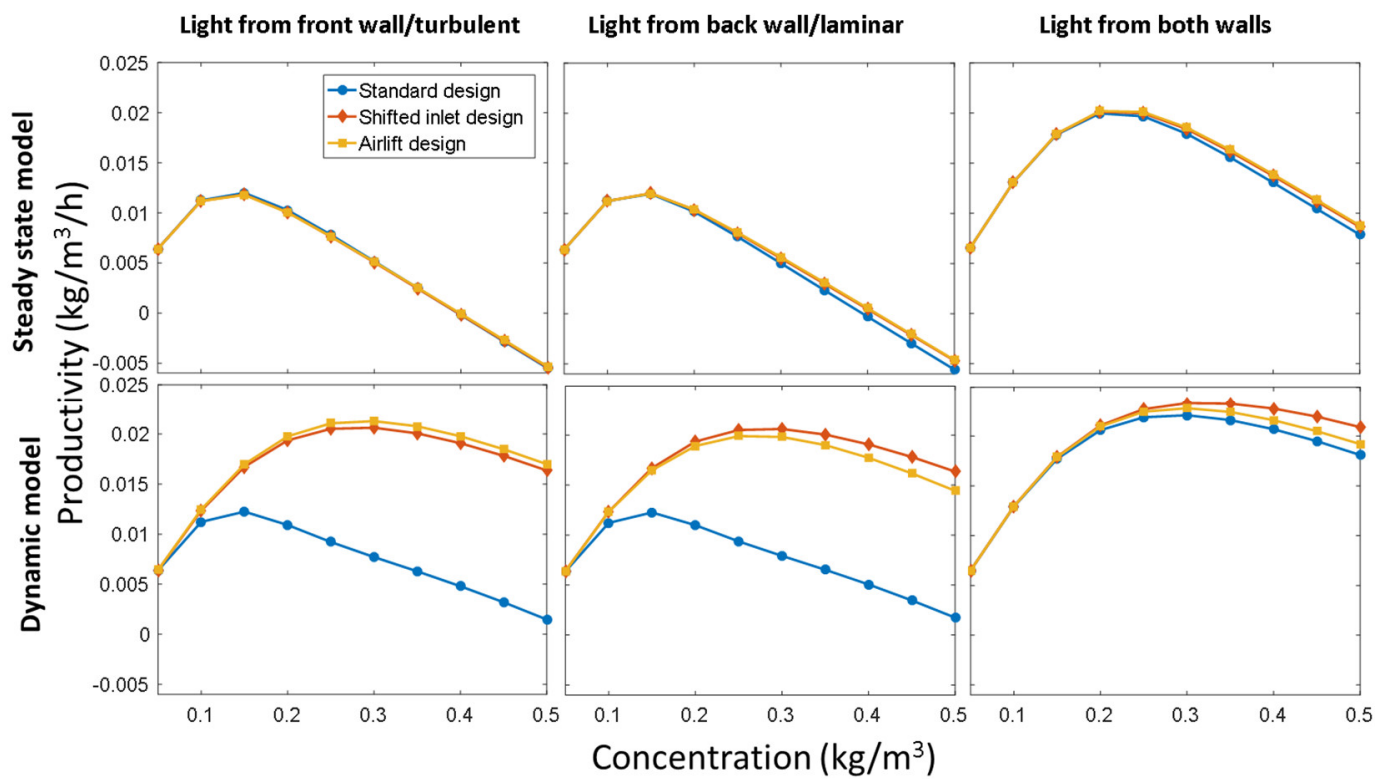

Figure 9. Biomass productivity at different microalgal concentrations for different light incidence schemes, different growth models, and different reactor designs. The parameter values used in the dynamic model were $k_{21}=0.1 \mathrm{~s}^{-1}$ and $k_{23}=10^{-4} \mathrm{~m}^{2} / \mu \mathrm{E}$, air inlet flowrate was $0.5 \mathrm{~L} / \mathrm{min}$, and incident light intensity was $1000 \mu \mathrm{E} / \mathrm{m}^{2} \mathrm{~s}$.

In conclusion, the microalgal concentration, interior design of the PBR, and light incident from both sides can be major factors in determining the productivity because they have an impact on the position of the L/D border and/or the dynamic light exposure.

Productivity is also affected by the parametrization of the dynamic growth model, i.e., the values of the two free parameters $k_{21}$ and $k_{23}$ (Figure 10). $k_{21}$ is crucial because it determines the rate of the photosynthetic process. A low value of $k_{21}$ signifies a slow process 
and thus a prominent effect of the light history. Such a low value was used in Figures 8 and 9 to demonstrate the impact of the light history of individual cells. With increasing $k_{21}$, a vanishing effect of light history led to a decrease in the biomass productivity of the PBR, and the result of the dynamic growth model approached the result of the steady state model (Figure 10a). $k_{23}$ accounts for the photo-inhibition process, and therefore did not affect the shape of the productivity curve but shifted it along the productivity axis (Figure 10b). Biomass productivity decreased on increasing the value of $k_{23}$ because of a faster photo-inhibition process, which more quickly damaged the cells. These effects occurred only when varying the parameters in orders of magnitude. Varying the values of these parameters within a 50\% range around a preset value did not affect the productivity curve much. Nonetheless, a better parameterization of the dynamic growth model used here, or an overall more detailed growth model, would be needed if a rigorous quantification of the relationship between biomass productivity and operational parameters is desired. Potentially, the workflow presented here could be used to improve growth model parameterization by inverse modeling.

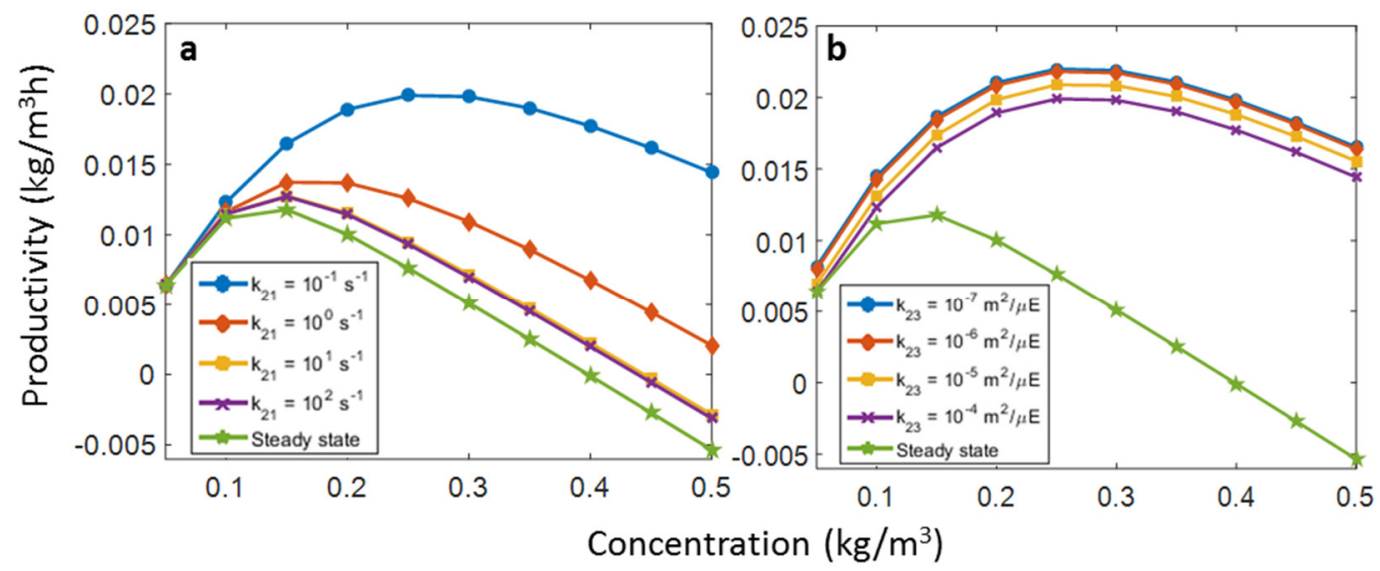

Figure 10. Effect of growth model parameters on biomass productivity of the PBR, depending on microalgal concentration, for Alternate Design A: (a) varying $k_{21}$ at $k_{23}=10^{-4} \mathrm{~m}^{2} / \mu \mathrm{E}$; (b) varying $k_{23}$ at $k_{21}=0.1 \mathrm{~s}^{-1}$. Air inlet flowrate was $0.5 \mathrm{~L} / \mathrm{min}$ and incident light intensity was $1000 \mu \mathrm{E} / \mathrm{m}^{2} \mathrm{~s}$.

\section{Conclusions}

Several parameters affecting the overall biomass productivity of a standard laboratory PBR were systematically studied in silico. Operational parameters such as air inlet flowrate and growth kinetic parameters only affected the productivity if they were varied in orders of magnitude, whereas a 50\% change in their values did not severely change the productivity. In contrast, design parameters such as the interior design and the light incident style strongly affected the productivity. Microalgal concentration and incident light intensities are interdependent parameters whose values significantly affected the productivity. A more reliable parameterization of dynamic algal growth modeling would help to better quantify these results.

Author Contributions: E.v.L. and G.H. designed the study, V.L. performed the simulations, all authors contributed to analyzing and discussing the results and preparing the manuscript. All authors have read and agreed to the published version of the manuscript.

Funding: This research was funded by the German Ministry of Education and Research (BMBF, grant number 03SF0465).

Data Availability Statement: The datasets generated and analyzed during the current study are available from the corresponding author upon reasonable request.

Conflicts of Interest: The authors declare no conflict of interest. 


\section{References}

1. Srivastava, R.K.; Shetti, N.P.; Reddy, K.R.; Aminabhavi, T.M. Biofuels, biodiesel and biohydrogen production using bioprocesses. A review. Environ. Chem. Lett. 2020, 18, 1049-1072. [CrossRef]

2. Rahman, M.M.; Mostafiz, S.B.; Paatero, J.V.; Lahdelma, R. Extension of energy crops on surplus agricultural lands: A potentially viable option in developing countries while fossil fuel reserves are diminishing. Renew. Sustain. Energy Rev. 2014, 29, 108-119. [CrossRef]

3. Gendy, T.S.; El-Temtamy, S.A. Commercialization potential aspects of microalgae for biofuel production: An overview. Egypt. J. Pet. 2013, 22, 42-51. [CrossRef]

4. Brännström, H.; Kumar, H.; Alén, R. Current and potential biofuel production from plant oils. BioEnergy Res. 2018, 11, 592-613. [CrossRef]

5. Von Cossel, M.; Wagner, M.; Lask, J.; Magenau, E.; Bauerle, A.; Von Cossel, V.; Warrach-Sagi, K.; Elbersen, B.; Staritsky, I.; Van Eupen, M.; et al. Prospects of bioenergy cropping systems for a more social-ecologically sound bioeconomy. Agronomy 2019, 9 , 605. [CrossRef]

6. Barros, M.V.; Salvador, R.; de Francisco, A.C.; Piekarski, C.M. Mapping of research lines on circular economy practices in agriculture: From waste to energy. Renew. Sustain. Energy Rev. 2020, 131, 109958. [CrossRef]

7. Nabel, M.; Temperton, V.M.; Poorter, H.; Lücke, A.; Jablonowski, N.D. Energizing marginal soils-The establishment of the energy crop Sida hermaphrodita as dependent on digestate fertilization, NPK, and legume intercropping. Biomass Bioenergy 2016, 87, 9-16. [CrossRef]

8. Olivieri, G.; Salatino, P.; Marzocchella, A. Advances in photobioreactors for intensive microalgal production: Configurations, operating strategies and applications. J. Chem. Technol. Biotechnol. 2014, 89, 178-195. [CrossRef]

9. Hamed, I. The evolution and versatility of microalgal biotechnology: A review. Compr. Rev. Food Sci. Food Saf. 2016, 15, 1104-1123. [CrossRef] [PubMed]

10. Solovchenko, A.; Verschoor, A.M.; Jablonowski, N.D.; Nedbal, L. Phosphorus from wastewater to crops: An alternative path involving microalgae. Biotechnol. Adv. 2016, 34, 550-564. [CrossRef]

11. Schreiber, C.; Schiedung, H.; Harrison, L.; Briese, C.; Ackermann, B.; Kant, J.; Schrey, S.D.; Hofmann, D.; Singh, D.; Ebenhöh, O.; et al. Evaluating potential of green alga Chlorella vulgaris to accumulate phosphorus and to fertilize nutrient-poor soil substrates for crops plants. J. Appl. Phycol. 2018, 30, 2827-2836. [CrossRef]

12. Mohsenpour, S.F.; Hennige, S.; Willoughby, N.; Adeloye, A.; Gutierrez, T. Integrating micro-algae into wastewater treatment: A review. Sci. Total Environ. 2021, 752, 142168. [CrossRef]

13. Khan, M.I.; Shin, J.H.; Kim, J.D. The promising future of microalgae: Current status, challenges, and optimization of a sustainable and renewable industry for biofuels, feed, and other products. Microb. Cell Fact. 2018, 17, 36. [CrossRef]

14. Loomba, V.; Huber, G.; Von Lieres, E. Biotechnology for Biofuels Single—Cell computational analysis of light harvesting in a flat-panel photo-bioreactor. Biotechnol. Biofuels 2018, 11, 1-11. [CrossRef]

15. Loomba, V. Modelling and Optimization of Algal Cultivation in Lab Scale Flat Panel Photobioreactors. PhD Thesis, RheinischWestfälische Technische Hochschule Aachen, Aachen, Germany, 2018.

16. Béchet, Q.; Shilton, A.; Guieysse, B. Modeling the effects of light and temperature on algae growth: State of the art and critical assessment for productivity prediction during outdoor cultivation. Biotechnol. Adv. 2013, 31, 1648-1663. [CrossRef] [PubMed]

17. Bitog, J.P.; Lee, I.-B.; Lee, C.-G.; Kim, K.-S.; Hwang, H.-S.; Hong, S.-W.; Seo, I.-H.; Kwon, K.-S.; Mostafa, E. Application of computational fluid dynamics for modeling and designing photobioreactors for microalgae production: A review. Comput. Electron. Agric. 2011, 76, 131-147. [CrossRef]

18. Bitog, J.P.P.; Lee, I.-B.; Oh, H.-M.; Hong, S.-W.; Seo, I.-H.; Kwon, K.-S. Optimised hydrodynamic parameters for the design of photobioreactors using computational fluid dynamics and experimental validation. Biosyst. Eng. 2014, 122, 42-61. [CrossRef]

19. Zhang, Q.; Wu, X.; Xue, S.; Liang, K.; Cong, W. Study of hydrodynamic characteristics in tubular photobioreactors. Bioprocess Biosyst. Eng. 2013, 36, 143-150. [CrossRef] [PubMed]

20. Zhang, Q.; Wu, X.; Xue, S.Z.; Wang, Z.H.; Yan, C.H.; Cong, W. Hydrodynamic characteristics and microalgae cultivation in a novel flat-plate photobioreactor. Biotechnol. Prog. 2013, 29, 127-134. [CrossRef]

21. Wang, L.-L.; Tao, Y.; Mao, X.-Z. A novel flat plate algal bioreactor with horizontal baffles: Structural optimization and cultivation performance. Bioresour. Technol. 2014, 164, 20-27. [CrossRef]

22. Wongluang, P.; Chisti, Y.; Srinophakun, T. Optimal hydrodynamic design of tubular photobioreactors. J. Chem. Technol. Biotechnol. 2013, 88, 55-61. [CrossRef]

23. Perner, I.; Posten, C.; Broneske, J. CFD Optimization of a plate photobioreactor used for cultivation of microalgae. Eng. Life Sci. 2003, 3, 287-291. [CrossRef]

24. Huang, J.; Li, Y.; Wan, M.; Yan, Y.; Feng, F.; Qu, X.; Wang, J.; Shen, G.; Li, W.; Fan, J.; et al. Novel flat-plate photobioreactors for microalgae cultivation with special mixers to promote mixing along the light gradient. Bioresour. Technol. 2014, 159, 8-16. [CrossRef]

25. Yu, G.; Li, Y.; Shen, G.; Wang, W.; Lin, C.; Wu, H.; Chen, Z. A novel method using CFD to optimize the inner structure parameters of flat photobioreactors. J. Appl. Phycol. 2009, 21, 719-727. [CrossRef]

26. Soman, A.; Shastri, Y. Optimization of novel photobioreactor design using computational fluid dynamics. Appl. Energy 2015, 140, 246-255. [CrossRef] 
27. Huang, J.; Feng, F.; Wan, M.; Ying, J.; Li, Y.; Qu, X.; Pan, R.; Shen, G.; Li, W. Improving performance of flat-plate photobioreactors by installation of novel internal mixers optimized with computational fluid dynamics. Bioresour. Technol. 2015, 182, 151-159. [CrossRef] [PubMed]

28. Gao, X.; Kong, B.; Vigil, R.D. Simulation of algal photobioreactors: Recent developments and challenges. Biotechnol. Lett. 2018, 40, 1311-1327. [CrossRef]

29. Nauha, E.K.; Alopaeus, V. Modeling algal cultivation in a bubble column photobioreactor. In Proceedings of the 14th European Conference on Mixing, Warszawa, Poland, 10-13 September 2012; pp. 335-340.

30. Pruvost, J.; Cornet, J.F.; Legrand, J. Hydrodynamics influence on light conversion in photobioreactors: An energetically consistent analysis. Chem. Eng. Sci. 2008, 63, 3679-3694. [CrossRef]

31. Gao, X.; Kong, B.; Vigil, R.D. Comprehensive computational model for combining fluid hydrodynamics, light transport and biomass growth in a Taylor vortex algal photobioreactor: Lagrangian approach. Bioresour. Technol. 2017, 224, 523-530. [CrossRef] [PubMed]

32. Tong, Z.X.; Li, M.J.; Yan, J.J.; Gu, Z.L. A theoretical analysis of the hydrodynamic influence on the growth of microalgae in the photobioreactors with simple growth kinetics. Int. J. Heat Mass Transf. 2020, 158, 119986. [CrossRef]

33. Nedbal, L.; Trtílek, M.; Červený, J.; Komárek, O.; Pakrasi, H.B. A photobioreactor system for precision cultivation of photoautotrophic microorganisms and for high-content analysis of suspension dynamics. Biotechnol. Bioeng. 2008, 100, 902-910. [CrossRef]

34. Huang, J.; Kang, S.; Wan, M.; Li, Y.; Qu, X.; Feng, F.; Wang, J.; Wang, W.; Shen, G.; Li, W. Numerical and experimental study on the performance of flat-plate photobioreactors with different inner structures for microalgae cultivation. J. Appl. Phycol. 2015, 27, 49-58. [CrossRef]

35. Nedbal, L.; Červený, J.; Keren, N.; Kaplan, A. Experimental validation of a nonequilibrium model of $\mathrm{CO}_{2}$ fluxes between gas, liquid medium, and algae in a flat-panel photobioreactor. J. Ind. Microbiol. Biotechnol. 2010, 37, 1319-1326. [CrossRef]

36. Rudnicki, P.; Gao, X.; Kong, B.; Vigil, R.D. A comparative study of photosynthetic unit models for algal growth rate and fluorescence prediction under light/dark cycles. Algal Res. 2017, 24, 227-236. [CrossRef]

37. Aiba, S. Growth kinetics of photosynthetic microorganisms. Adv. Biochem. Eng. 1982, 23, 85-156.

38. Eilers, P.H.C.; Peeters, J.C.H. A model for the relationship between light intensity and the rate of photosynthesis in phytoplankton. Ecol. Model. 1988, 42, 199-215. [CrossRef]

39. Olivieri, G.; Gargiulo, L.; Lettieri, P.; Mazzei, L.; Salatino, P.; Marzocchella, A. Photobioreactors for microalgal cultures: A Lagrangian model coupling hydrodynamics and kinetics. Biotechnol. Prog. 2015, 31, 1259-1272. [CrossRef]

40. Wu, X.; Merchuk, J.C. A model integrating fluid dynamics in photosynthesis and photoinhibition processes. Chem. Eng. Sci. 2001, 56, 3527-3538. [CrossRef]

41. Zarmi, Y.; Bel, G.; Aflalo, C. Theoretical Analysis of Culture Growth in Flat-Plate Bioreactors: The Essential Role of Timescales. In Handbook of Microalgal Culture: Applied Phycology and Biotechnology, 2nd ed.; Richmond, A., Hu, Q., Eds.; John Wiley \& Sons, Ltd.: Hoboken, NJ, USA, 2013; pp. 205-224.

42. Schreiber, C.; Behrendt, D.; Huber, G.; Pfaff, C.; Widzgowski, J.; Ackermann, B.; Müller, A.; Zachleder, V.; Moudříková, Š.; Mojzeš, P.; et al. Growth of algal biomass in laboratory and in large-scale algal photobioreactors in the temperate climate of western Germany. Bioresour. Technol. 2017, 234, 140-149. [CrossRef]

43. Perner-Nochta, I.; Posten, C. Simulations of light intensity variation in photobioreactors. J. Biotechnol. 2007, 131, 276-285. [CrossRef]

44. Cornet, J.F. Calculation of optimal design and ideal productivities of volumetrically lightened photobioreactors using the constructal approach. Chem. Eng. Sci. 2010, 65, 985-998. [CrossRef]

45. Qiang, H.; Zarmi, Y.; Richmond, A. Combined effects of light intensity, light-path and culture density on output rate of Spirulina platensis (Cyanobacteria). Eur. J. Phycol. 1998, 33, 165-171. [CrossRef]

46. Muller-Feuga, A.; Le Guédes, R.; Hervé, A.; Durand, P. Comparison of artificial light photobioreactors and other production systems using Porphyridium cruentum. J. Appl. Phycol. 1998, 10, 83-90. [CrossRef] 